\title{
EL NARRADOR JOSË REVUELTAS, LA TIERRA Y LA HISTORIA
}

\author{
POR \\ EDITH NEGRIN \\ Universidad Nacional Autónoma de México
}

Uno de los escritores que construye la narrativa mexicana contemporánca, rompiendo con la linealidad y el simplismo de muchas de las novelas y relatos de las primeras décadas de cste siglo, cs José Revucitas (1914-1976). La obra de cste cscritor no cs, lamentablemenic, muy conocida fucra de las fronteras nacionales.

La figura de Revueltas ha adquirido rasgos legendarios por su biografia política: paradigma del intelectual contestatario, en un medio en cl cual es ésa una actitud poco común. La militancia comunista en varias organizaciones fuc una constante en su existencia. Conoció la prisión, en la forma de un reformatorio juvenil, a los 14 años; fuc encarcclado, por última vez a los 54, cn la Cárcel de Lecumberri - hoy Archivo General de la Nación- donde permancció 3 años. Entre ambos confinamientos hubo otros, a las Islas Marías, así como otras manifestaciones de represión, por parte del poder. Innmerso en la participación política, practicando desde cl activismo más elemental hasta la más compleja reflexión teórica. Revucltas produjo una obra original, cuya cvaluación como totalidad está por hacerse.

Sus obras completas, recopiladas como tales después de su mucrie', abarcan 25 tomos que incluyen, además de sus escritos literarios, cartas y apuntes, los artículos periodísticos y los ensayos políticos y filosóficos.

Por lo que hace a la literatura, es en la novela y el relato donde Revueltas alcanza sus mejores momentos; aunque algunas de sus crónicas periodísticas siguen vigentes por la calidad de su prosa ${ }^{2}$. Escribió también teatro, c hizo algunos accrcamicntos a la pocsía.

\footnotetext{
'La edición de las Obras Completas de José Revueltas ha estado a cargo de la Editorial ERA (México). El primer volumen, reedición de la novela Los muros de agua, apareció en 1978. Los dos últimos, bajo el título de Las evocaciones requeridas I y II, que incluyen material parcialmente inédito, diarios, cartas, apuntes, se publicaron en 1987.

2 Por ejemplo la "Visión del Paricutín", crónica que Revueltas publicara en 1943 sobre la explosión del volcán, ha sido incluida por Carlos Monsiváis en su Antología de la crónica en México (México: UNAM, 1979).
} 
El autor publicó su primer relato,"Foreign Club", en 1938, y el último, "Hegel y yo ..." en 1974. En algo más de 3 décadas de escritura narrativa vio la publicación de 7 novelas, Los muros de agua (1941), El luto humano (1943), Los días terrenales (1949), En algún valle de lágrimas (1956), Los motivos de Caín (1957), Los errores (1964), El apando (1969), y 3 colecciones de relạtos, Dios en la tierra (1944), Dormir en tierra (1960) y Material de los sueños (1974).

El seguimiento cronológico de estas obras va perfilando a un sujeto narrador a la vez muy sensible al acontecer histórico y persistente en unas cuantas obsesiones. Así, si por encima de los títulos, principios y finales que, sustentados en la materialidad de un determinado número de páginas, scñalan los límitcs de cada cuento o novela, consideramos el conjunto de esta producción como un sólo texto, encontramos que éste posce una gran unidad y coherencia.

Uno de los clementos de esta unidad es la actitud hermenćutica del narrador; su convicción de que, ocultos por la superficie perceptibie de la vida cotidiana, se encuentran los significados verdaderos.

Dos obsesiones fundamentales y fundadoras entran en juego, se oponen y a la vez se complementan, ramificando por todo cl tejido tex tual. Una cs la indagación sobre la condición humana, cuya sola enunciación sugiere intemporalidad. La otra es la historia que horada la intemporalidad y redefine constantemente al hombre. Si la militancia política de Revucltas esluvo vertebrada por la convicción de que los hombres hacen su historia, sus tex tos litcrarios muestran una tensión entre csta premisa y su cuestionamiento. Tal tensión se convierte en un centro generador de la litcratura revucltiana.

En cste contexto, pienso que una incisión en el sistema de vasos comunicantes constituido por esta narrativa, que sirva de entrada a su compleja problemálica, cs la dialéctica entre la ticrra y $\mathrm{cl}$ desarraigo.

\section{DE "LOS DIAS TERRENALES"}

En 1972, entrevistado por la periodista Margarita García Flores, Josć Revueltas dijo:

Yo hubiera querido denominar a toda mi obra Los días terrenales. A excepción tal vez de los cuentos, toda mi novelística se podría agrupar bajo el denominativo común de Los días terrenales, con sus diferentes nombres: El luto humano, Los muros de agua, etcétera. Y tal vez a la postre eso vaya a ser lo que resulte, en cuanto la obra esté terminada o la dé yo por cancelada y decida ya no volver a escribir novela o me muera y ya no pueda escribirla. Es prematuro hablar de eso, 
pero mi inclinación sería ésa y esto le recomendaría a la persona que de causalidad esté recopilando mi obra, que la recopile bajo el nombre de Los días terrenales ${ }^{3}$.

La idea de dar un título a la totalidad de su corpus novelístico sugiere la plena conciencia de su madurez como escritor, por parte de Revucltas. En 1967 había aparccido una compilación de sus obras narrativas publicadas hasta entonces, autorizada y prologada por él mismo, que se titula simplemente Obra literariat.

Lo cierto es que, al momento de la entrevista, cl autor ya casi había finalizado su producción narrativa; tres años antes había publicado El apando, su última novela y uno de sus textos más perfectos.

Dos años despućs de su cntrevista con Margarita García Flores, daría a la imprenta una colección de relatos, Material de los sueños; pero de los 7 cuentos que integran el libro, 4 habian sido ya incluidos en la Obra literaria y $2 \mathrm{sc} \mathrm{habían} \mathrm{dado}$ a conocer en revistas.

El cscritor falleció en 1976. Sus palabras sobre la denominación de su universo de novelas bien pueden considerarse una especie de última voluntad; y así parecen haberlo hecho los coordinadores de sus obras completas; cada novela lleva como epígrafe la cita mencionada.

La sugerencia del nombre deseado por Revucltas luce ahora, a cierta distancia icmporal, accrtada, aún por lo que hace a los relatos —en mi opinión-, pesc a las rasgos espécíficos que éstos presentan. El elemento tierra tiene que ver con la problemática de muchos de los cuentos y está en cl título de las dos primcras colcccioncs, Dios en la tierra, Dormir en tierra. En la 3a. colccción, cl volumen más abicrtamente onírico del escritor, este clemento ha dejado una huclla $\mathrm{cn}$ la voluntad de conferir aun a lo imaginario un asidero terrenal, Material de los sueños.

"Los días terrenales", que cs asimismo el título de la 3a. novela de Revucltas, considerada por él la mejor, es una frase que conduce de inmediato a las imágenes y los acontecimientos de la narración bíblica: cl paraíso terrenal, el primer pecado, la expulsión de Adán y Eva. Otros nombres de novelas, En algún valle de lágrimas, Los motivos de Caín, hacen explícito tambićn el sustrato bíblico que informa la obra revueltiana.

Así, cl desticrro del paraíso de la primera pareja, como origen simbólico de la humanidad, es un hecho fundamental para la narrativa de Revucltas. La dialéctica entre la ticra y el desarraigo, la culpa que condena al hombre a vivir crrante, aparecen, bajo diversos ropajes, en relatos y novelas.

\footnotetext{
${ }^{3}$ Margarita García Flores, "José Revueltas: entre lúcidos y atormentados", en Diorama de la Cullura, suplemento de Excelsior (México: 16 de abril de 1972).

${ }^{4}$ José Revueltas, Obra literaria (en dos tomos).(México: Empresas Editoriales, 1967).
} 
A partir de este hecho fundador, la expulsión del edén de los primeros hombres, el sustantivo tierra adquiere en el universo del autor un carácter polisémico. Con frecuencia este sustantivo va acompañado de un verbo asimismo crucial: pertenecer. Por oposición a estos términos, el destierro, la no-pertenencia, van configurando, a lo largo de los textos una espacialidad del desamparo humano.

Para comprender en toda su significación el funcionamicnto de la ticrra y lo ierrenal en esta narrativa, es necesario enmarcarlo dentro de la tematización de la infinitud y el desamparo.

\section{LA INFINITUD, EL DESAMPARO}

Desde los escritos iniciales hasta los últimos, es evidente en el narrador Revucltas la preocupación por el desamparo en que los hombres se encuentran y que sucle vincularse con la conciencia de la infinitud. Algunos cjemplos.

En la primera novela, Los muros de agua (1941), uno de los personajes positivos, la militante comunista Rosario, cvoca su adolescencia; en clla, a las muchas frustraciones se añadía cl terror ante la noción del infinito que sus cstudios de matemáticas le revelaran. Recucrda Rosario:

\footnotetext{
[la maestra] repetía con voz aguda y chillona la fórmula de la circunferencia, y aquello sonaba tan extraño que era extremadamente difícil penetrar el sentido de pronto místico, absurdo- de lo que quería explicar. "Phi por $R$ al cuadrado", luego "tres, calorce, diecisćis". Por qué aquella desoladora propensión al infinito?
}

En la vivencia de la adolescente hay un eco del conocido aforismo de Pascal: "El silencio cterno de csos espacios infinitos me espanta". Así, en la angustia de Rosario se encuentra el germen de la visión trágica de Revuclas, que lo vincula con el pensamiento existencialista. La infinitud es tempo-espacial en la concepción del filósofo cristiano; lo cs también cn la del escritor comunista. En las narraciones de Revucltas lo infinito se opone, por una parte, a la historia, y por otra, a la ticrra.

En otro pasaje de la misma novcla, cl infinito está simbolizado por cl mar. Uno de los personajes, durante la travesía que va a conducirlo a las Islas Marías, reflexiona:

5 José Revueltas, Los muros de agua, 1941 (México: ERA, 1981), p.58.

- Blaise Pascal, Pensamientos (Madrid: Alianza Editorial, 1981), p.81. 
porque el océano Pacífico era, sin duda, el más viejo de los mares, el primero de todos ellos , cuando en el mundo no había tierra y todo consistía solamente en un errar sin meta y sin principio (p.45).

La condición errante, que en este fragmento se asocia a la ausencia de tierra, y en otras narraciones a la carencia de tierra propia, cs una actitud frecuente de los personajes revuctianos. En una novela que el escritor no llegó a terminar, El tiempo y el número, cuyo primer capílulo se publicó en 19687, de nuevo el mar significa lo infinito. 'El tiempo' y 'el número' a que alude el título son, desde mi punto de vista, en base a los fragmentos que se conservan del texto, las formas con que el hombre enfrenta la infinitud.

En algunas de las obras el infinito se concretiza en descripciones de espacios siderales, donde impera la ingravidez.

Así, en el relato "La palabra sagrada" (Dormir en tierra), la protagonista se oculta en un polvoriento desván y lo percibe como un "universo absurdo ... entre los mucrtos planctas". Ella se siente como "cl ángel del tiempo ... inspector de las ruinas siderales"; y ante un globo terráqueo reflexiona "el ángel del tiempo miró con profunda pena a esta culpable esfera"s.

En la novela Los errores se habla también de "tiradero sideral"".

La falta de contacto con la tierra en algunas ocasiones asume la forma de la angustiosa sensación abismal a la que aluden repetidamente en sus reflexiones $\mathrm{el}$ narrador y los personajes. En cl volumen Dios en la tierra, uno de los relatos se llama "El abismo"10.

Las diversas formas de decir el infinitivo van sicmpre unidas a la angustia, a la conciencia que los hombres cobran de su desamparo, de su radical inseguridad - csta última es una de las caractcrísticas definitorias de la visión trágica del mundo" ${ }^{11}$ Estos antecedentes nos permiten abordar ya la problemática de la ticrra.

${ }^{7}$ El primer capítulo de El tiempo y el número, publicado en 1967, así como el segundo, aparecido en 1975, están en el volumen de las obras completas titulado Las Cenizas (México: ERA,1981). Este volumen recoge relatos publicados en revistas, o inéditos, y fragmentos de narraciones.

${ }^{8}$ José Revucltas, "La palabra sagrada", en Dormir en tierra, 1960. (México: ERA, 1982), pp. 27, 28.

'José Revueltas, Los errores, 1964 (México: ERA, 1980), p. 44.

10 José Revucltas, "El abismo", en Dios en la tierra, 1944, (México: ERA, 1979).

${ }^{11}$ De acuerdo al filósofo contemporáneo Walter Kaufmann, que ha revisado las distintas teorizaciones sobre la tragedia, un factor constante, definitorio en la visión trágica del mundo es la 'inseguridad radical del hombre'. Véase Walter Kaufmann, Tragedia y filosofía (Barcelona: Seix Barral, 1978), pp. 186-187. 


\section{LA TIERRA, LA HISTORIA}

Un texto que resume la polisemia de la ticrra en la narrativa de Revucitas es su segunda novcla, El luto humano.

La anécdota de la novela se desenvuelve en dos planos temporales, presente y pasado; ambos relatados por un narrador omnisciente.

El presente de la novela se ubica, mediante numerosos indicadores, en la década de los treinta, en un pucblo mexicano. En este plano del presente, los acontecimientos son escasos, despaciosos y reiterativos. Unos cuantos campesinos, uras la muerte de la única niña del pueblo, emprenden, junto con un sacerdote, la búsqueda de un nucvo lugar en donde cstablecerse. En juego intertextual con la Biblia, al viaje de los campesinos se le llama 'éxodo' , y al sitio que persiguen, 'tierra prometida'.

De hecho el pucblo estaba ya casi desicrto, a causa de la miscria que sucedió a unos breves años de bienestar, proporcionados por los beneficios de la reforma agraria cstatal. Los pocos que quedaban emigran, muerta la única niña del pucblo y tratando de huir de una tormenta, especic de diluvio bíblico que, a la postre, los vence.

La caminata de los campesinos en el presente pierde pronto su objetivo y se vuclve circular; simulitáncamente, cl tiempo de la acción se va cmpantanando hasta desembocar en la ahistoricidad ${ }^{12}$. Al final de este viaje agónico, los hombres, enemistados entre sí, esperan inmóviles la muerte, refugiados en el techo de una casa, desde donde contemplan a unos zopilotes que, a su vez, los observan ávidamente.

La sucesión de los hechos del presente es interrumpida con frecuencia, estacionada por las reflexiones de los personajes, atravesada por sus recucrdos que, al complementarse, van conformando el plano del pasado.

A la inversa de lo que ocurre en el presente, cl plano del pasado está informado por la historicidad. Integrados los fragmentos, presentan un panorama de la historia del siglo XX en momentos significativos: los años finales de la dictadura porfirista, la lucha armada de la revolución de 1910, la gucra religiosa protagonizada por campesinos mexicanos, cntre 1926 y 1929; y la cstabilización del sistema político surgido de la Revolución. Tal estabilización se manifiesta en la reforma agraria, que vive una de sus mejores etapas en los treinta. La reforma agraria

\footnotetext{
${ }^{12}$ En mi opinión, quien mejor ha estudiado la función del tiempo y la historicidad en El luto humano es Antoine Rabadán, cuyos lineamientos al respecto sigo en términos generales. Véase Antoine Rabadán, El luto humano de José Revuellas, (México: Editorial Domés, 1985).
} 
conllevó la instalación de un sistema de riego que produjo un efímcro bienestar a los habitanites del pucblo en que ocurre la acción de El luto humano; es el antecedente inmediato del plano del presente.

En la novela se alude también a ouros hechos históricos que no llegan a significar la introducción de nuevos planos temporales y que funcionan más en un sentido simbólico que estrictamente histórico. Así, hay referencia a la conquista y a la colonización de México, pero sobre todo como el origen simbólico de la nacionalidad mexicana. Por otra parte, la voz del narrador omnisciente, evoca, hacia el final de la novela, la revolución soviética de 1917-a través de la mención de Stalin-pero como una esperanza: como culminación de un proceso que, cn cl curso de la trama, quedó frustrado.

Por los grupos sociales a que pertenecen casi todos los personajes, campesinado y lumpenproletariado, cl recorrido por la historia nacional se hace desde la óptica de los desposeídos, si bien se complejiza con la única perspectiva distinta, la del cura, que se identifica por completo con el narrador omnisciente. $Y$ el hilo conductor del recorrido de csta historia es la búsqueda de cspacio vital, por parte de estos desposcídos, cspacio vital simbolizado por la ticrra.

La historia vivida por los personajes se inicia con un acto de desarraigo. A principios del siglo $\mathrm{XX}$, despućs de una lucha fallida de un grupo de indígenas yaquis por defender paric de su territorio, varias familias fucron obligadas a emigrar a otra parte del pais. Una mujer indígena, al verse desterrada, opta por no seguir viviendo:

vinieron "pelones" para llevarse muy lejos a las familias, que por orden del supremo gobierno.

Las condujeron hasta la estación del ferrocarril ... Era abandonar la ticrra, dejar todo.

La madre de Antonia tuvo un gesto sombrío. El tren, pausado, aproximábase como una bestia de fuego.

-No vamos, es mejor morir - dijo la madre de Antonia, y tomando de los pies a su hijo de un año lo estrelló contra la vía del ferrocarril

- Eres una víbora, india hija de la chingada! -exclamó un soldado, a tiempo que la atravesaba con la bayoneta ${ }^{13}$.

No es casual que el niño muricra en la vía del ferrocarril, pues éste era el cmblema de la incipiente industrialización del país, del progreso a que aspiraba la dictadura porfirista.

${ }_{13}$ José Revueltas, El luto humano, 1943, (México: ERA, 1981), pp.62-63. Salvo otra aclaración, todos los subrayados en el texto son míos E.N. 
A partir de esta escena se establece una relación que va a ser constante en la obra: la pérdida de la tierra equivale a la pérdida de la identidad y conduce a la mucrte. En el contexto de la trama, el fallecimiento del niño simboliza el final de la raza indígena, final que supone el nacimiento de una nueva raza. La hermana del niño, Antonia, única sobreviviente de la familia, tiene una existencia signada por la necrofilia - "rodeada por la muerie, hecha para la muerte"(p.63)_; pero va a tencr un hijo, fecundada por un hacendado español. Tras esta repetición del mestizaje mítico, todos los personajes mexicanos van, en adelante, a ser mestizos.

En el desarrollo de la historia, la tierra se liga con otro elemento, la religión. Sc implica que cl mestizaje no sólo cambió la identidad de los mexicanos, sino que destruyó sus sentimientos religiosos:

Algo quedó faltándole al pueblo desde entonces. La tierra, el dios, Tlaloc, la sierra sí (p.171).

La religión se articula y se imbrica con la tierra para constituir ese 'algo' de que los mexicanos, entonces indigenas, fucron despojados por la conquista y la colonización españolas. La gucra cristera mexicana se trata, cn la novcla, como un movimiento campesino que intentaba recuperar ese 'algo'. El sacerdote describe las atrocidades que, por parte de ambos bandos, se cometicron cn esta gucra, y comenta:

¿Qué pueblo asombroso, qué puebio espantoso? Sólo podía explicarse por la desposesión radical y permanente de que habia sido objeto el hombre, que si defendía a Dios era porque en él defendía la vaga, temblorosa, empavorecida noción de sentirse dueño de algo, dueño de Dios, dueño de la iglesia, dueño de las piedras, de algo que jamás había poseldo, la tierra, la verdad, la luz, o quien sabe que, magnífico y poderoso (p.172).

El sentido del vínculo entre ticrra y religión se esclarece si se tiene presente la definición que el narrador, a propósito del cura, ofrece de esta última, "lo religioso tenía para su iglesia un sentido cstricto y litcral: religare, ligarse, atarse" (p. 29, en cursiva en el texto). Se esclarece, asimismo, si se recuerda que la religión, como elemento aglutinador, como enlace entre los hombres, antecede al nacionalismo ${ }^{14}$. En esta perspectiva, la religión, junto con la ticrra, cobran todo su sentido. A los mexicanos les ha sido arrebatada la religión, no sólo en tanto espacio de

\footnotetext{
${ }^{14}$ Sobre la función histórica de la religión y el nacionalismo como enlaces entre los hombres, véase Benedict Anderson, Imagined Communities, (Londres: Verso Editions, 1983), pp. 18-19.
} 
comunicación y de unidad con entidades trascendentes, sino en tanto espacio de comunicación y de unidad de los hombres entre sí. Es decir, fueron despojados del 'algo' que la religión, junto con la tierra, significan: cl cspacio vital, la comunidad, la identidad, cl país, la nación; en breve, la patria.

Así, El luto humano presenta el surgimiento -en el plano del pasado-y la agonia - en el del presente - de una nación, México, desde la óplica de los campcsinos, de los oprimidos.

La revolución de 1910, la guerra cristera, la construcción del sistema de riego durante la reforma agraria, presentan a las masas unidas luchando por su ticrra y la posibilidad de trabajarla. El presente de la trama muestra a un puñado de hombres desunidos $\mathrm{e}$ indiferentes.

Las masas que lucharon, en la revolución de 1910, por la tierra ${ }^{15}$ - lo cual es decir, por la patria-la obtuvicron cuando, gracias a la política agraria del régimen, recibicron la ticrra y la forma de explotarla gracias al sistema de ricgo. Pero fue un logro clímero. Una combinación de factores sociales, en que causas y efectos se confunden, conduce el sistema de riego al fracaso y a los hombres a la miscria. Se describe la deficiente construcción del sistema; cl asesinato del personaje más positivo de la novela, Natividad, líder comunista con rasgos cristianos, a manos de un mercenario del gobierno; la incapacidad de los hombres para establecer entre sí relaciones solidarias. El éxodo de los habitantes del pueblo, que sucede a la decadencia del proyecto, implica que los campesinos pierden la patria que habían creído conquistar. La muerte de la pequeña Chonita, que abre la novela, es un acontecimiento similar al de la mucrte del niño que significaba la aniquilación de la raza indígena; pero en el presente la aniquilación será definitiva. A partir de la mucrte de la niña, cancelado cl futuro, las fucrzas de la muerte se han instaladoentre los personajes.

La relación entre la tierra y la identidad de los hombres se mantiene en esta temporalidad del presente de la novela, y en ambas predomina la negatividad. Se reitcra la identificación de las mujeres con la tierra; algunos ejemplos:

Cecilia era la tierra, las quince hectáreas de Ursulo ... era la tierra de México (p.186).

${ }^{15}$ La lucha por la tierra fue, en efecto uno de los fundamentos de la revolución de 1910. José Revucltas reitera este tema en un exıenso - y aún no filmado- guión cinematográfico sobre la vida y lucha de Emiliano Zapata, llamado precisamente Tierra y libertad (México: ERA, 1981). 
todo lo que pasaba afuera, el rumor del viento, la lluvia, el río, lo sentía dentro de sí la Calixta, como si ella fuera la tierra (p.89).

[la Borrada] Malintzin de tierra, otra vez en la tierra (p.128).

Se cstablece una analogía entre la esterilidad de la tierra y la de las mujeres en el plano del presente - y en este contexto la esterilidad es otra forma de decir la muerte. En la misma escena, la del velorio de Chonita, se presenta la parodia siniestra de una mujer encinta en la figura de una campesina hidrópica, y se informa de la carencia de flores en el pucblo:

La Calixta parecía embarazada a causa de la hidropesía y su flacura; de esta suerte cra extraordinaria y como más sucia ...

Nadie llevó flores - sólo Jerónimo una botella de tequila que a todos ofrecía con su mirada húmeda y lierna- porque la pobreza era muy grande y flores no se podían encontrar en sitio alguno (pp. 33-34).

La ticrra y los hombres mexicanos, fruto de un mestizaje impuesto, de una falta đe integración, tienen atributos contradictorios:

así era la tierra de este país: tierna, cruel, hostil, cálida, fría, acogedora, indiferente, mala, agria, pura (p.29).

Fuera de cllos [Ursulo, Adán, Cecilia, Chonita] el paisaje parecía el mismo e interior paisaje que llevaban dentro, desesperanzado, contradictorio (p.29).

Lo dominante, lo definitorio de la ticrra, en el presente cs cl carácter necrofílico, y del paisaje se ha extendido a todo cl país:

tierra avara y yerma: extensiones de cal dura y sin misericordia donde florecían las calaveras de los caballos y escuchábase el seco rumor de las culebras sedientas; desgracia de tierra apenas con sus cactos llenos de ceniza y agrio jugo de lágrimas remotas, hundidas en lejana geología (p.26).

Y este país cra un país de mucrtos caminando, hondo país en busca del ancla, del sostén secreto (p.25).

De ahi que, cuando en el viaje del presente los campesinos renuncian a buscar 'cl ancla', 'cl sostén secreto', 'la ticrra prometida', la patria, cl tiempo se empantana y desemboca en la ahistoricidad. A la progresiva aniquilación de la 
historia corresponde la progresiva desaparición de la ticrra bajo la inundación. Los personajes se ven forzados a subir a la azotea, porque el agua ha cubierto la superficie de ticrra.

En El luto humano, en síntesis, la tierra entra en jucgo con la comunidad, la identidad, la religión, la historia y la patria, en una combinatoria compleja cn la que los elementos, en dinamismo constante, se aproximan, complementan, imbrican o confunden en diversos momentos de la narración. Esta articulación de factores tiene un signo positivo, con una sola excepción, la tendencia necrofílica que es común a la tierra y a los hombres mexicanos en cl plano del presente.

En csta visión que sitúa en la conquista y la colonización, en cl mestizaje forzado, la negatividad de origen de la nación mexicana es objeto de las reflexiones del narrador y los personajes:

Tenía Adán esa sangre envenenada, mestiza, en la cual los indígenas veían su propio miedo y encontraban su propia nostalgia imperecedera, su pavor retrospectivo, cl naufragio de que aún tenían memoria (p.18).

Mientras persistiera el símbolo trágico de la serpiente y el águila, del veneno y la rapacidad, no habría esperanza. Se había escogido lo más atroz para representar -y tan cabal, tan patéticamente - la patria absurda, donde el nopal, con sus flores sangrientas cra fidedigno y triste, los brazos exiendidos por encima del agua, cruz extraña y tímida, india y resignada (p.36).

La concepción de que estos fragmentos dan muestra, entronca con la filosofía de él y lo mexicano, corriente que ha tenido diversos momentos en el panorama del pensamicnto nacional, y uno de cuyos textos seminales en el presente siglo es $E l$ perfil del hombre y la cultura en México, de Samucl Ramos, publicado en 1934. La misma prececupación por explicar la especificidad de los mexicanos mediante herramientas sicológicas c históricas a que responde el cnsayo de Ramos, se detecta cn la novela de Revucltas.

Sin cmbargo, incluso en el plano presente de El luto humano, en cl que la ticra aparece ligada a la negatividad, esta negatividad no es total; cl verdadero desastre del pucblo y la mucrte de sus habitantes se produce cuando se separan de su ticra y renuncian a buscar otra. Justamente uno de los problemas de esta ctapa es que los hombres se habían mostrado incapaces de explotar amorosamente la ticrra.

Lo que domina en el texto y en el resto de la obra de Revueltas es la visión positiva de la tierra, y la articulación de elementos negativos que a clla se oponen incluye cl desticrro, el desarraigo, la desubicación, el vacío, la ahistoricidad, la infinitud. 
Lesde el punto de vista de las ideas, lo definitorio de los textos narrativos de Revueltas es la tensión paradójica entre dos sistemas de pensamiento contemporánco, el existencialismo y $\mathrm{cl}$ marxismo. Por lo que hace a la ticrra, clla y los clementos que a su alrededor se agrupan, se vincularían con el marxismo dos de tales elementos, historia y comunidad, son reveladores de esa vinculación. A su vez, los elementos relacionados con la ausencia de tierra se conectarían con cl existencialismo, en un sentido muy lato.

\section{PERTENECER}

En 1943, cuando poco despućs de la publicación de El luto humano, José Revuclas recibió el Premio Nacional de Litcratura, lcyó, en una reunión de escritores, un texto que confirma la visión de la tierra que se desprende de esta novela y de otras narraciones. El texto se titula "El escritor y la ticrra", y se inicia así:

La primera condición del escritor - hay que decir también del carpintero, del albañil-, la primera condición del hombre es pertenecer. Parece obvio, pero al hombre se le dijo esta primera palabra de pertenecer y también se le dijo a la piedra y al árbol. El árbol pertenece, está ubicado, tiene un sitio. Nada más simple, nada más evidente y prodigioso. Entonces hay que cumplir con la palabra ardiente de pertenecer. Y quien es el escritor, que manos tiene para estar por encima de las cosas, por encima del desorden, él, representante, que debiera ser representante, del desorden, del caos, de la lucha, de las tinieblas que quieren llegar a convertirse en luz?

Hay que tomar nuestro vestido de tierra, nosotros féretros que tenemos pasos, y comprometernos ligándonos al mundo.

\section{Y finaliza:}

Quiénes somos para no pertenecer?

Nuestra primera condición es esiar en la tierra ${ }^{15}$.

${ }^{16} J o s e ́$ Revueltas, "El escritor y la tierra" en Visión del Paricutín (y otras crónicas y reseñas), (México: ERA, 1983), pp. 205-206. 